\title{
Trials Assessing Parmacotherapeutic Management of Aggression in Psychiatric Patients: Comparability with Clinical Practice
}

Authors

Affiliations
L. E. Goedhard ${ }^{1,2}$, J. J. Stolker ${ }^{2,3}$, H. L. I. Nijman ${ }^{1,4}$, T. C. G. Egberts ${ }^{2,5}$, E. R. Heerdink ${ }^{1,2,5}$

Affiliation addresses are listed at the end of the article

\section{received $\quad 05.07 .2009$ \\ revised $\quad 05.01 .2010$ \\ accepted $\quad 08.03 .2010$}

Bibliography

DOI http://dx.doi.org/

10.1055/s-0030-1254091

Published online ahead of print

Pharmacopsychiatry

(c) Georg Thieme Verlag KG

Stuttgart · New York

ISSN 0176-3679

Correspondence

\section{E. R. Heerdink}

Utrecht University

Faculty of Science

Utrecht Institute for

Pharmaceutical Sciences

Division of Pharmacoepidemiol-

ogy \& Pharmacotherapy

PO Box 80082

3508 TB Utrecht

The Netherlands

Tel.: + 31-3025 37324

Fax: + 31-302539166

E.R.Heerdink@uu.nl

\section{Abstract}

$\nabla$

Introduction: In a previous review of randomized controlled trials (RCTs) on the pharmacotherapeutic management of aggression, it was shown that there is only weak evidence of effectiveness. In the present study we aim to determine comparability of patients included in these RCTs and patients of psychiatric long-stay wards.

Methods: Exclusion criteria that were used in at least $20 \%$ of the RCTs were applied to a sample of aggressive inpatients from clinical practice, in

\section{Introduction}

$\nabla$

Aggression is an important issue in mental health departments, as it negatively influences the wellbeing of both patients and staff workers and results in high costs $[4,21]$. Pharmacotherapy is one of the tools used to prevent or reduce aggressive behaviour and incidents. Our group has shown that only weak empirical evidence is available for the effectiveness of pharmacotherapeutic management of aggression [18]. This systematic review was restricted to randomized controlled trials (RCTs) as these are considered to be the gold standard to obtain the most valid evidence for the effect of interventions [38]. However, one of the observations from the review was that characteristic aggressive patients seen in clinical practice may be different from those included in RCTs, because of recruitment procedures depending on voluntary participation, strict inclusion and exclusion criteria, and sometimes small populations. This selection process may hamper the comparability of RCT populations to daily clinical practice patients, as has been shown by others, especially in psychiatric populations. Zimmerman [44], for example, showed that only $14 \%$ of depressed patients seen order to find what proportion of these patients would be eligible to participate in the reviewed, high quality RCTs.

Results: Only 30\% of aggressive psychiatric patients as seen in clinical practice would be eligible to participate in a typical randomized controlled trial based on the most frequently applied exclusion criteria.

Discussion: The low comparability of patients included in RCTs with those seen in clinical practice may decrease the generalizability of the findings form RCTs to clinical practice.

in daily practice would qualify for trial participation when applying exclusion criteria that are commonly used in RCTs. Another recent study showed that in patients suffering from epilepsy, less than thirty percent would qualify to participate in a standard RCT [39].

In the present study we aim to determine the comparability of patients in RCTs investigating the maintenance pharmacotherapy for those patients in whom aggression is an ongoing problem, with patients of psychiatric long-stay wards.

\section{Patients and Methods \\ $\nabla$ \\ RCTs}

In a previously published paper, we reviewed the literature for RCTs assessing the pharmacotherapeutic maintenance therapy of aggression [18]. In brief, these trials were retrieved by searching Pubmed, EMBASE, Psyclit and Cochrane up to March 2004, using MESH terms covering both "aggression" (including aggression-related symptoms like violence) and pharmacotherapy (including the different psychotropic drug classes). These RCTs [1-3,5-13,15-17, 19, 20, 23- 
Table 1 Exclusion criteria used in the RCTs.

\begin{tabular}{|lcc|}
\hline Exclusion criteria & $\begin{array}{l}\text { Percentage of all trials in which } \\
\text { the criterion was used }\end{array}$ & $\begin{array}{c}\text { Percentage of trials, conducted in inpatient } \\
\text { setting, in which the criterion was used }\end{array}$ \\
\hline substance abuse (alcohol or drugs) & 54.8 & 44.4 \\
\hline abnormal routine laboratory values & 51.6 & 66.7 \\
\hline clinically relevant systemic somatic disorder (heart, renal, & 51.6 & 61.1 \\
hepatic, neurological, asthma and COPD) & & 33.3 \\
pregnancy & 38.7 & 16.7 \\
\hline use of other psychotropics than the study drug & 35.5 & 27.8 \\
\hline lactating & 32.2 & 0.0 \\
\hline suicidal ideation & 19.3 & 11.1 \\
\hline without contraception & 16.1 & 16.7 \\
\hline unstable medical disorder & 16.1 & 38.9 \\
\hline organic brain disorder & 9.7 & 0.0 \\
\hline psychotherapy & 9.7 & 16.7 \\
\hline depot neurolepticum & 9.7 & 0.0 \\
\hline women & 6.4 & 0.0 \\
\hline men & 3.2 & 0.0 \\
\hline history of psychiatric hospitalization & 3.2 & 5.6 \\
\hline IQ < 75 & 3.2 & 5.6 \\
\hline drug-induced psychosis & 3.2 & 0.0 \\
\hline self-mutilation & 3.2 & \\
\hline
\end{tabular}

30,32-37,40-43] studied the pharmacological management of aggression in adult (18-65 years old) psychiatric patients in general psychiatric settings. This means that RCTs applying to specialized psychiatric settings - like child psychiatry, mental retardation, and organic brain diseases - or to non-psychiatric settings - like prisons - were not included in this review. For this review, only those RCTs of sufficient methodological quality, which was defined as a Jadad score [22] of three or more, were selected for the present study.

The selected 31 RCTs $[1-3,5-8,10-13,17,19,20,23-25,27-$ $30,32-37,40-43$ ] with sufficient quality were reviewed for applied exclusion criteria.

\section{Clinical practice sample}

The population sampled from clinical practice consisted of all patients of three long-stay wards of Altrecht Mental Health Care Institute who engaged in aggressive behaviour during admission. The three participating wards were units for forensic psychiatry, a centre for intellectually disabled adolescents and adults with severe disruptive behaviour, and a ward for juveniles with externalizing behaviour disorders. Aggressive behaviour on these wards was continuously monitored and recorded by the staff using the staff observation aggression scale-revised (SOASR) [31]. Patients eligible for our study populations had all had been admitted for at least two weeks during the period September 2004 until December 2005. Patients with one or more aggressive incidents during the study period, as recorded with the SOAS-R, were selected.

For consenting patients, physical examination, medical history and laboratory values were determined during the first week of admission. These data as well as demographic information were extracted from the hospital records.

The study protocol was approved by the Institutional Review Board of the hospital.

\section{Data analysis}

All selected RCTs were reviewed and all exclusion criteria that were used in at least six $(20 \%)$ of the 31 RCTs were selected. Subsequently, these criteria were applied to the sample of aggres- sive inpatients from clinical practice, in order to calculate what proportion of these patients would be eligible to participate in the reviewed, high quality RCTs. Lastly, characteristics of eligible patients were compared with characteristics of ineligible patients.

As the patients from clinical practice were all inpatients, a subanalysis, with the use of only the exclusion criteria used in at least $20 \%$ of the RCTs conducted in inpatient settings, was performed.

\section{Results \\ $\nabla$ \\ RCTs}

The RCTs were conducted in the following patient groups: schizophrenic patients ( $\mathrm{N}=12$ [39\% of the RCTs]) and patients with cluster B personality disorder ( $\mathrm{N}=12$ [39\% of the RCTs), patient ssuffering from PTSD ( $\mathrm{N}=3[10 \%$ of the RCTs]), depressive disor$\operatorname{der}(\mathrm{N}=2[7 \%$ of the RCTs]), ADHD ( $\mathrm{N}=1$ [3\% of the RCTs]) and autistic disorder ( $\mathrm{N}=1[3 \%$ of the $\mathrm{RCTs}]$ ).

The exclusion criteria extracted from the RCTs are presented in 8 Table 1.

A number of exclusion criteria, including "relevant somatic disorder", "physical disorder", "unstable medical disease" and "abnormal routine lab", were generally not well-defined. The authors of studies in which these exclusion criteria were not well-defined, were contacted by e-mail for further specification of these criteria. Response rate was low ( 3 out of $15=20 \%$ ). On basis of the responses and the other reviewed RCTs in which somatic illnesses or deviant laboratory values as exclusion criteria were defined more precisely, we decided to further specify the criteria as follows: "relevant somatic disorder", "physical disorder" and "unstable medical disease" included neurological diseases, COPD and asthma, cardiovascular disease, liver disease and renal failure, whereas "abnormal routine lab" comprised deviant laboratory tests findings, including liver function, kidney function, thyroid function and haemogramme.

The exclusion criterion "the use of psychotropics other than the study medication" was used in $58 \%$ of the trials with borderline 


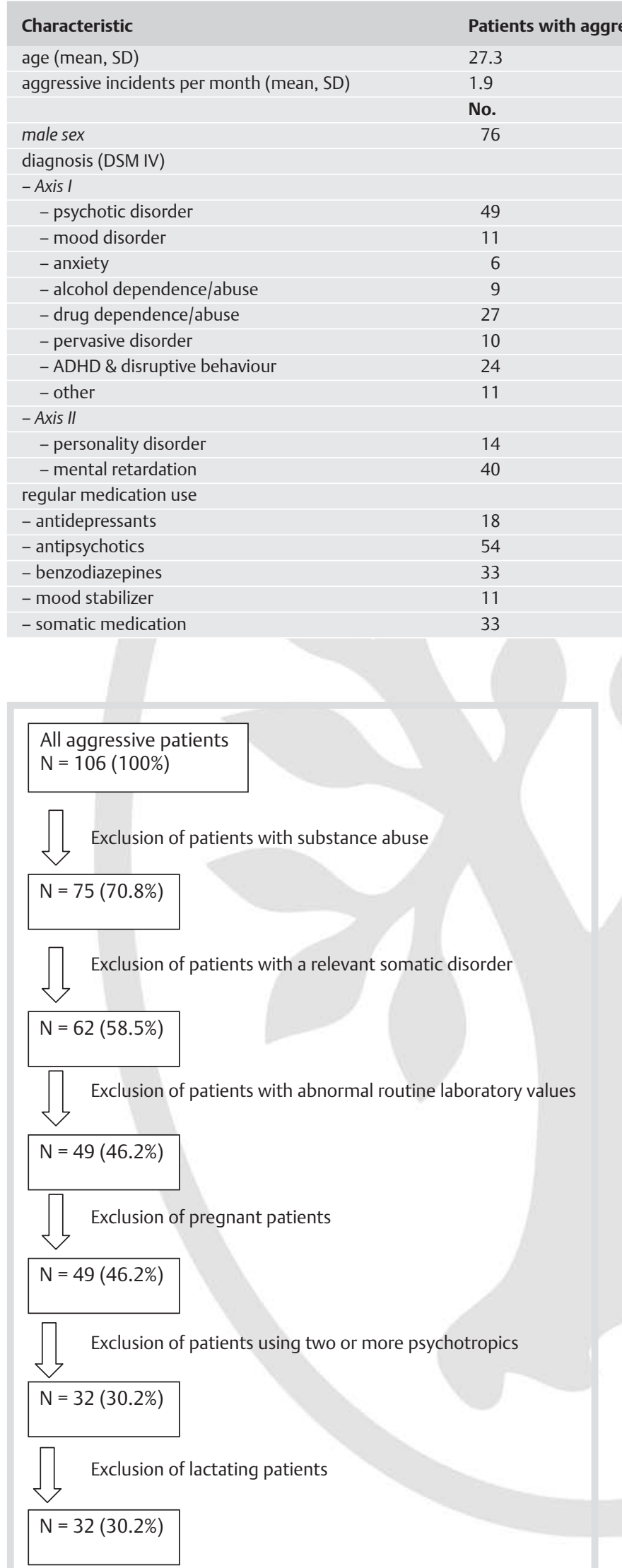

Fig. 1 Sequential application of exclusion criteria to the whole group of patients.
Table 2 Clinical practice sample. patients, but in none of the trials conducted in a study population consisting of schizophrenic patients.

\section{Clinical practice sample}

The clinical practice sample consisted of 106 aggressive patients. Patients' characteristics are displayed in - Table 2. Exclusion criteria were applied in descending order of appearance in the trials. Current drugs and/or alcohol abuse was observed in $29 \%$ of the patients. Fourteen patients $(13 \%)$ had a relevant somatic disorder. Furthermore, three patients (3\%) refused to undergo a physical examination, which would be reason for exclusion in an RCT. Abnormal routine lab was observed in $13 \%$ of the patients, whereas $5 \%$ of the patients refused to give a blood sample. No patients were pregnant or lactating. Finally, in several studies patients were excluded if other psychotropics were used concomitantly with the study drug. We assumed that patients from our study sample using two or more psychotropics would not likely be switched to only one study-drug. Therefore, from our study sample patients using more than one psychotropic, i.e., almost one third (34\%), were considered ineligible for a trial. With the application of these criteria on the study population, only $30 \%$ of the patients would be eligible for trial participation ( $\bullet$ Fig. 1). As use of other psychotropics was not a frequently used exclusion criterion in the RCTs conducted in patients with schizophrenia, we also calculated the percentage of eligible schizophrenic patients, without application of this criterion, which resulted in a percentage of $43 \%$ of patients that would be eligible.

Lastly, in the subanalysis in which only exclusion criteria of the RCTs conducted in inpatients setting were applied to the clinical practice sample, $46 \%$ of patients appeared to be eligible.

\section{Eligible versus ineligible patients}

The eligible patients were compared with the ineligible patients, results of this comparison are shown in $\bullet$ Table 3.

Eligible patients were significantly younger and were less frequently diagnosed with a personality disorder. Concerning the 
Table 3 Comparison of eligible and ineligible patients.

\begin{tabular}{|c|c|c|c|c|c|}
\hline \multirow[t]{2}{*}{ Characteristic } & \multicolumn{2}{|c|}{ Included patients } & \multicolumn{2}{|c|}{ Excluded patients } & \multirow[t]{2}{*}{ P-value } \\
\hline & N & (\%) & $\mathbf{N}$ & (\%) & \\
\hline age (mean, SD) & 23.5 & 9.9 & 28.9 & 10.3 & 0.003 \\
\hline aggressive incidents per 100 days (median) & 4.2 & & 2.5 & & 0.19 \\
\hline severely aggressive & 28 & $(87.5)$ & 55 & $(74.3)$ & 0.13 \\
\hline male sex & 20 & $(62.5)$ & 56 & 75.7 & 0.17 \\
\hline \multicolumn{6}{|l|}{ diagnosis (DSM IV) } \\
\hline \multicolumn{6}{|l|}{ - axis I } \\
\hline - psychotic disorder & 11 & $(34.4)$ & 38 & $(51.4)$ & 0.11 \\
\hline - mood disorder & 4 & $(12.5)$ & 7 & (9.5) & 0.64 \\
\hline - pervasive disorder & 6 & $(18.8)$ & 4 & (5.4) & 0.06 \\
\hline - ADHD \& disruptive behaviour & 11 & $(34.4)$ & 13 & $(17.6)$ & 0.06 \\
\hline \multicolumn{6}{|l|}{ - axis II } \\
\hline - personality disorder & 2 & $(6.2)$ & 17 & $(23)$ & 0.04 \\
\hline - mental retardation & 10 & $(31.2)$ & 30 & $(40.5)$ & 0.37 \\
\hline
\end{tabular}

frequency and severity of aggression, no differences were observed between eligible and ineligible patients.

\section{Discussion \\ $\nabla$}

The current results suggest that, based upon the most frequently applied exclusion criteria, only $30 \%$ of aggressive psychiatric patients as seen in clinical practice would be eligible to participate in a typical randomized controlled trial investigating the pharmacological maintenance treatment of aggression. This finding is in line with the proportions reported in two previous studies, in which $14 \%$ and $30 \%$ of patients from clinical practice were found to be eligible for trial participation in a clinical practice population treated for depression and epilepsy, respectively $[39,44]$.

These findings warrant the conclusion that the evidence for the pharmacological management of aggression not only appears to be weak [18] but that, additionally, the patients in trials are different from the patients of clinical practice, or at least different from typical psychiatric long-stay inpatients. Subsequently this raises the question whether the trial outcomes are generalizable to clinical practice. It is quite well imaginable that they are not. For example, it is likely that more somatic comorbidity influences the generalizability of trials, e.g., due to the use of comedication. Furthermore, comparison of the group of the eligible with the non-eligible patients shows that the eligible patients differ from the non-eligible patients, at least for diagnosis and age.

In addition to the exclusion criteria applied, other characteristics of the evaluated RCTs are likely to decrease the comparability of trials to clinical practice. Firstly, previous research suggests that aggressive patients are less likely to give informed consent [14]. This might lead to an underrepresentation of severely aggressive patients. Furthermore, the setting of many RCTs ( $40 \%$ in outpatient departments) and the recruitment methods (e.g., advertisement) might also have contributed to an underrepresentation of severely aggressive patients in the RCTs. It is well imaginable that the aetiology of aggression of severely aggressive patients differs from the aetiology in mildly aggressive patients, thereby requiring different pharmacotherapeutic strategies.

In conclusion, it is likely that the low comparability of the patients in RCTs with the patients from practice affects the gen- eralizability of the efficacy of trial medication and observed side effects. However, with the available data we were not able to investigate this. To investigate this, other research, such as conducted by Wisniewski et al. [45], is needed. In that study the researchers showed that depressive patients who would be ineligible for a phase III trial with antidepressants, experienced more severe side effects and had lower remission and response rates compared to the eligible patients.

From a clinical point of view we therefore conclude that it might be understandable that with only weak evidence for efficacy, psychotropics are used (off-label) in an attempt to manage such a difficult behaviour as aggression. However, from our point of view, prescribers should be well aware of the limited available evidence with a probable low generalizability to clinical practice, and certainly stop the medication if no effect is observed.

This study has some limitations. The criterion "multiple psychotropic use" was observed in the trials conducted in populations consisting of patients with cluster B personality disorder, but not in the trials conducted in populations consisting of schizophrenic patients. The percentage of patients that could be included in a study would increase to $46 \%$ if multiple psychotropic use would be allowed. This suggests that an analysis, stratified for diagnosis would be more appropriate. However, the number of included trials was not enough to conduct such an analysis.

Furthermore, because the methodology of the trials was not always clearly described, we may have interpreted the criteria concerning somatic disorders and abnormal routine laboratory values not strictly enough or too strictly when cut-off points were not mentioned in the RCTs. Future studies possibly could give more insight, with the current regulations binding researchers to publish their study protocols in an internet database.

\section{Conclusion}

With an eligibility percentage of $30-46 \%$, we conclude that the patient comparability of trials, investigating the pharmacological management of aggression, to clinical practice is low. Furthermore, other RCT characteristics suggest that patients displaying severe aggression are not eligible in RCTs. The low comparability may decrease the generalizability of RCT findings to clinical practice. 


\section{Acknowledgements \\ $\nabla$}

We gratefully acknowledge Lieke Goumans for contributing to the data collection.

\section{Affiliations}

${ }^{1}$ Altrecht Institute for Mental Health Care, Den Dolder, The Netherlands ${ }^{2}$ Department of Pharmacoepidemiology and Pharmacotherapy, Utrecht Institute for Pharmaceutical Sciences (UIPS), Faculty of Science, Utrecht, The Netherlands

${ }^{3}$ Arkin Institute for Mental Health Care, Amsterdam, the Netherlands

${ }^{4}$ Academic Center of Social Sciences, Radboud University Nijmegen, The Netherlands

${ }^{5}$ Department of Clinical Pharmacy, Division Laboratory and Pharmacy, University Medical Center Utrecht, Utrecht, The Netherlands

\section{References}

1 Allan ER, Alpert M, Sison CE et al. Adjunctive nadolol in the treatment of acutely aggressive schizophrenic patients. J Clin Psychiatry 1996; 57: 455-459

2 Alpert M, Allan ER, Citrome L et al. A double-blind, placebo-controlled study of adjunctive nadolol in the management of violent psychiatric patients. Psychopharmacol Bull 1990; 26: 367-371

3 Blin O, Azorin JM, Bouhours P. Antipsychotic and anxiolytic properties of risperidone, haloperidol, and methotrimeprazine in schizophrenic patients. J Clin Psychopharmacol 1996; 16: 38-44

4 Caldwell $A$. Hospital accountability: perceptions and costs. Front Health Serv Manage 1992; 8: 38-40

5 Caspi N, Modai I, Barak P et al. Pindolol augmentation in aggressive schizophrenic patients: a double-blind crossover randomized study. Int Clin Psychopharmacol 2001; 16: 111-115

6 Citrome L, Casey DE, Daniel DG et al. Adjunctive divalproex and hostility among patients with schizophrenia receiving olanzapine or risperidone. Psychiatr Serv 2004; 55: 290-294

7 Citrome L, Volavka J, Czobor P et al. Effects of clozapine, olanzapine, risperidone, and haloperidol on hostility among patients with schizophrenia. Psychiatr Serv 2001; 52: 1510-1514

8 Coccaro EF, Kavoussi RJ. Fluoxetine and impulsive aggressive behavior in personality-disordered subjects. Arch Gen Psychiatry 1997; 54: 1081-1088

9 Czobor P, Volavka J, Meibach RC. Effect of risperidone on hostility in schizophrenia. J Clin Psychopharmacol 1995; 15: 243-249

10 Davidson JR, McLeod MN, Turnbull CD et al. A comparison of phenelzine and imipramine in depressed inpatients. J Clin Psychiatry 1981; 42: 395-397

11 Davidson JR, Landerman LR, Farfel GM et al. Characterizing the effects of sertraline in post-traumatic stress disorder. Psychol Med 2002; 32: 661-670

12 de la Fuente JM, Lotstra F. A trial of carbamazepine in borderline personality disorder. Eur Neuropsychopharmacol 1994; 4: 479-486

13 Dorrego MF, Canevaro L, Kuzis G et al. A randomized, double-blind, crossover study of methylphenidate and lithium in adults with attention-deficit/hyperactivity disorder: preliminary findings. J Neuropsychiatry Clin Neurosci 2002; 14: 289-295

14 Edlund MJ, Craig TJ, Richardson MA. Informed consent as a form of volunteer bias. Am J Psychiatry 1985; 142: 624-627

15 Fassino S, Leombruni P, Daga G et al. Efficacy of citalopram in anorexia nervosa: a pilot study. Eur Neuropsychopharmacol 2002; 12: 453-459

16 Fava $M$, Nierenberg AA, Quitkin FM et al. A preliminary study on the efficacy of sertraline and imipramine on anger attacks in atypical depression and dysthymia. Psychopharmacol Bull 1997; 33: 101-103

17 Frankenburg F, Zanarini M. Divalproex sodium treatment of women with borderline personality disorder and bipolar II disorder: a doubleblind placebo-controlled pilot study. J Clin Psychiatry 2002; 63: 442-446

18 Goedhard LE, Stolker JJ, Heerdink ER et al. Pharmacotherapy for the treatment of aggressive behavior in general adult psychiatry: A systematic review. J Clin Psychiatry 2006; 67: 1013-1024

19 Hollander E, Allen A, Lopez RP et al. A preliminary double-blind, placebo-controlled trial of divalproex sodium in borderline personality disorder. J Clin Psychiatry 2001; 62: 199-203

20 Hollander E, Tracy KA, Swann AC et al. Divalproex in the treatment of impulsive aggression: efficacy in cluster B personality disorders. Neuropsychopharmacology 2003; 28: 1186-1197
21 Hunter $M$, Carmel $H$. The cost of staff injuries from inpatient violence. Hospital and Community Psychiatry 1992; 43: 586-588

22 Jadad AR, Moore RA, Carroll D et al. Assessing the quality of reports of randomized clinical trials: is blinding necessary? Control Clin Trials 1996; 17: 1-12

23 Lipman RS, Covi L, Rickels $K$ et al. Imipramine and chlordiazepoxide in depressive and anxiety disorders. I. Efficacy in depressed outpatients. Arch Gen Psychiatry 1986; 43: 68-77

24 Maoz G, Stein D, Meged S et al. The antiaggressive action of combined haloperidol-propranolol treatment in schizophrenia. European Psychologist 2000; 5: 312-325

25 Marder SR, Davis JM, Chouinard G. The effects of risperidone on the five dimensions of schizophrenia derived by factor analysis: combined results of the North American trials. J Clin Psychiatry 1997; 58: 538-546

26 Mattes JA. Comparative effectiveness of carbamazepine and propranolol for rage outbursts. J Neuropsychiatry Clin Neurosci 1990; 2: 159-164

27 McDougle CJ, Naylor ST, Cohen DJ et al. A double-blind, placebo-controlled study of fluvoxamine in adults with autistic disorder. Arch Gen Psychiatry 1996; 53: 1001-1008

28 Min SK, Rhee CS, Kim CE et al. Risperidone versus haloperidol in the treatment of chronic schizophrenic patients: a parallel group doubleblind comparative trial. Yonsei Med J 1993; 34: 179-190

29 Monnelly EP, Ciraulo DA, Knapp C et al. Low-dose risperidone as adjunctive therapy for irritable aggression in posttraumatic stress disorder. J Clin Psychopharmacol 2003; 23: 193-196

30 Nickel MK, Nickel C, Mitterlehner FO et al. Treatment of aggression with topiramate in male borerline patients: a double-blind, placebo-controlled study. Biol Psychiatry 2005; 57: 495-499

31 Nijman $H$, Muris $P$ et al. The staff observation aggression scale Revised (SOAS-R). Aggress Behav 1999; 25: 197-209

32 Peuskens J. Risperidone in the treatment of patients with chronic schizophrenia: a multi-national, multi-centre, double-blind, parallelgroup study versus haloperidol. Risperidone Study Group. Br J Psychiatry $1995 ; 166$ : 712-726 ; discussion 727-733

33 Ratey JJ, Sorgi P, O'Driscoll GA et al. Nadolol to treat aggression and psychiatric symptomatology in chronic psychiatric inpatients: a double-blind, placebo-controlled study. J Clin Psychiatry 1992; 53: 41-46

34 Rinne T, van den Brink W, Wouters L et al. SSRI treatment of borderline personality disorder: a randomized, placebo-controlled clinical trial for female patients with borderline personality disorder. Am J Psychiatry 2002; 159: 2048-2054

35 Salzman C, Wolfson AN, Schatzberg A et al. Effect of fluoxetine on anger in symptomatic volunteers with borderline personality disorder. J Clin Psychopharmacol 1995; 15: 23-29

36 Soloff PH, George A, Nathan S et al. Amitriptyline versus haloperidol in borderlines: final outcomes and predictors of response. J Clin Psychopharmacol 1989; 9: 238-246

37 Soloff PH, George A, Nathan RS et al. Progress in pharmacotherapy of borderline disorders. A double-blind study of amitriptyline, haloperidol, and placebo. Arch Gen Psychiatry 1986; 43: 691-697

38 Starfield B. Quality-of-care research: internal elegance and external relevance. JAMA 1998; 280: 1006-1008

39 Tlusta E, Handoko KB, Majoie $M$ et al. Clinical relevance of patients with epilepsy included in clinical trials. Epilepsia 2008; 49: 1479-1480

40 van der Kolk BA, Dreyfuss D, Michaels $M$ et al. Fluoxetine in posttraumatic stress disorder. J Clin Psychiatry 1994; 55: 517-522

41 Vartiainen H, Tiihonen J, Putkonen A et al. Citalopram, a selective serotonin reuptake inhibitor, in the treatment of aggression in schizophrenia. Acta Psychiatr Scand 1995; 91: 348-351

42 Zanarini MC, Frankenburg FR. Olanzapine treatment of female borderline personality disorder patients: a double-blind, placebo-controlled pilot study. J Clin Psychiatry 2001; 62: 849-854

43 Zanarini MC, Frankenburg FR, Parachini EA. A preliminary, randomized trial of fluoxetine, olanzapine, and the olanzapine-fluoxetine combination in women with borderline personality disorder. J Clin Psychiatry 2004; 65: 903-907

44 Zimmerman M, Mattia JI, Posternak MA. Are subjects in pharmacological treatment trials of depression representative of patients in routine clinical practice? Am J Psychiatry 2002; 159: 469-473

45 Wisniewski SR, Rush AJ, Nierenberg AA et al. Can phase III trial results of antidepressant medications be generalized to clinical practice? A STAR*D Report. Am J Psychiatry 2009; 166: 599-607 